\title{
Reform of Applied Talents Training of Electronic and Information Engineering under the Background of New Engineering Course
}

\author{
Yanwu LIU*, Zhilin ZHU, Shouxiang ZHANG, Lijie FAN, Fan WANG and Xinmiao DING \\ School of Information and Electronic Engineering, Shandong Technology and Business University \\ Yantai, Shandong 264005
}

\begin{abstract}
The Electronic and Information Engineering of Shandong Technology and Business University has constructed a unique application-oriented talents training system in order to effectively solve the single practice mode in the process of talent training and effectively improve students' practical ability and innovative ability. Through reforming talents training system, especially strengthening practical teaching links; implementing innovation and entrepreneurship education and collaborative education, comprehensively promoting innovative teaching system construction, and integrating training the innovation consciousness and innovation ability into each teaching link, a teaching system of electronic and information engineering with the training of innovation and practice ability as the main line will be formed. Practice has proved that the featured applied talents training system of the Electronic and Information Engineering has effectively improved students' practical ability and innovative ability, and significantly improved the employability, employment quality and employment rate of graduates.
\end{abstract}

Keywords-Electronic and information engineering; Talent training; Teaching system; Practical ability; Innovation capacity

\section{INTRODUCTION}

In 2017, the Ministry of Education launched the "New Engineering Course" development and research work, the "Construction of Fudan Consensus with 'New Engineering Course"' was formed on February 18, and the "New Engineering Course" Action Route was formed on April 8 (Tianda Action)". The Beijing Guide was formed on June 9. The leaders of the Higher Education Department of the Ministry of Education have repeatedly stressed that it is necessary to focus on the national development strategy, grasp the new situation and tasks of talent training in colleges and universities, comprehensively deepen the reform of higher engineering education, accelerate the construction of new engineering course, actively face the future, and adapt to and lead the new economy. The new engineering course construction has set off a new wave of reforms in China's higher education sector, and various universities have responded in succession [1], which has also caused great repercussions in industry and internationally.

\section{RESEARCH SIGNIFICANCE}

In February 2018, the Implementation Planning of New and Old Kinetic Energy Conversion Major Project in Shandong Province was released, clearly proposing the JinanQingdao-Yantai Tri-core test area of the new and old kinetic energy conversion in Shandong Province, and in terms of the new generation of information technology as the leader of the top ten industries, the undergraduate colleges are encouraged to carry out the construction of applied new engineering courses.

The electronic and information engineering major actively focuses on delivering excellent innovative applied talents for regional economic construction around the main development line of "serving localities and facing applications", with the training of high-level applied talents in the field of electronic and information who have good quality and social responsibility, continuous learning and development ability, stronger professional ability and innovative ability as the goal, and with electronic technology and embedded application technology as the main talent training direction, to provide excellent innovative and applied talents for regional economic construction.

Under this background, the research on the training mode of applied talents in electronic and information engineering under the new engineering course background is of great significance for promoting the training of new engineering course electronic and information talents and serving the regional economic development and the old and new kinetic energy transformation [2].

\section{TALENT TRAINING SCHEME AND CURRICULUM SYSTEM}

A. Optimize the professional talent training scheme and construct a comprehensive curriculum system combined with characteristics of multi-disciplinary development of our university and the advantages of the economic management discipline in our university according to the university characteristics.

(1) Revise the professional talent training scheme taking the opportunity of promoting the credit system reform by the university, and thoroughly implement the credit system. 
(2) Organize courses with engineering ability as the core and professional knowledge as the basis, integrate the projectbased ability training, active learning and experiential learning into a series of professional courses, put focus on the training of engineering ability and build a modular curriculum system.

(3) Further promote the reform of enterprise research and personnel training mode in terms of curriculum, jointly develop curriculum implementation scheme jointly by university and enterprises, regularly adjust and improve the curriculum outline, and make enterprise experts and university teachers teach courses jointly.

\section{B. Construct a multi-perspective integrated teaching environment based on cognitive science}

Help students to correctly understand the conceptual system of the discipline through the teaching methods combining theoretical teaching with project practice and the timely evaluation and feedback mechanism. Improve the students' communication and collaboration abilities through the team-focused and project-driven practice learning system [3].

The electronic and information courses are strongly theoretical and practical usually, and it is difficult for the students to accept them. The students' cognition and practical abilities can be improved through project training.

\section{Build MOOC and mixed innovation and entrepreneurship courses}

Select one course from five curriculum module systems such as the basic physics, electronic circuit, signal processing, programming and intelligent control finely, and build $\mathrm{MOOC}+$ SPOC.

A mixed innovation and entrepreneurship open course will be constructed. The Innovation and Entrepreneurship Open Course adopts a mixed teaching program, which includes MOOC learning, private cloud data collaboration, proprietary cloud desktop, and internal discussion forum, etc. The multistage assessment and dynamic elimination mechanism will be adopted.

\section{Enrich the MOOC function by using the comprehensive university cloud education platform}

Traditional MOOCs ignore the interaction between teachers and students and cannot call local educational resources. The university plans to introduce the Internet of Things + education innovation mode, and build a comprehensive teaching platform integrating MOOC, educational resource management, teaching management, virtual simulation experiment environment, training certification mechanism and experimental resource scheduling achieve the real cloud education mode of "listening, leaning, training, discussion and evaluation".

\section{CONSTRUCTION OF TEACHERS' TEAM}

(1) The university will proactively contact with cooperative enterprises, select key teachers to participate in teacher training classes and technical exchange meetings, select key teachers in batches to take a temporary post and undergo practice at fixed posts in enterprises, improve the teachers' technical level and teacher ability, and build a new type of "double-teacher type" teacher team.

(2) Professional leaders will actively participate in the Summit Talent Training Forum and the New Engineering Course Construction Conference on the Teaching Guidance Committee of the Ministry of Education, and take the initiative to learn lessons and make exchange in brother colleges and universities.

(3) Professional backbone teachers will actively participate in the Curriculum Teaching Reform Conference sponsored by the Teaching Guidance Committee of the Ministry of Education, and understand and master the issues related to the curriculum system and curriculum construction of the new engineering course.

(4) The university will hire outstanding professional and technical talents of cooperative enterprises as part-time teachers. The university will cooperate with colleges and universities in teacher training classes, technical meetings, teacher training, etc., improve the teachers' technical level and faculty's ability, cooperate with colleges and universities in teacher training classes, technical meetings and teacher post training, etc., and improve the teachers' technical level the teacher's ability.

\section{TEACHING METHODS AND MEANS}

\section{A. Joint guidance and comprehensive training of school and enterprise}

In terms of engineering ability and innovation ability, the university is required to train the students according to the general standards and industry standards and more in-depth participation of industry enterprises is also required. The university plans to introduce gold medal lecturers and project cases of the enterprise at the end of each semester to conduct comprehensive training on university students at this major, and train students' engineering ability, design ability and innovation ability through continuous and gradual typical engineering projects suitable for teaching and improve employability. The enterprise lecturers will be mainly selected and hired from the enterprises with which the cooperative relationships have been established in order to explore the establishment of the cooperation mode of industry-university cooperation combining campus teaching with off-campus training [4].

The university will establish a perfect comprehensive and practical training management mechanism at the end of term in order to monitor various aspects such as enterprise access, project review, campus tutor participation, and training quality assessment, further utilize the high-quality resources of the enterprise and improve the quality of the practical training. 


\section{B. Teaching methods and means of practice system}

The university will integrate scientific research, engineering application and enterprise resource, use laboratories and internship training bases, and build experimental and practical teaching systems for electronic information with projects and technologies as driving force. The university will also strengthen the practical teaching links such as internships, professional and comprehensive practice, extracurricular scientific and technological activities, academic competitions, professional internships, professional skill certification and graduation design.

\section{1) Conduct project-based practice teaching reform}

Under the background of constructing "double-teacher type" teachers, the project-based teaching has the dual role of improving students' practical ability and teachers' teaching ability. The university will set up open application projects and innovation and entrepreneurship projects guided by social demands through the in-depth docking with enterprises. Under the guidance of professional teachers, the students can build teams according to their own characteristics, complete project design, research, development and production, and write summaries and reports. Finally, the jury committee will check and accept it through competition or result presentation, etc. The whole process will closely combine the relevant courses and the practical application of the enterprise, stimulate the students' potential, enhance the team's team awareness and collaboration ability, and train students' professional quality and professional ethics.

\section{2) Build practice teaching base and improve engineering} practice ability

The university will continue to consolidate the software and hardware environment of the practice teaching base in the university, strengthen cooperation with industry, localities and enterprises, introduce more high-level and high-tech enterprises in order to build an internship training base, establish an integrated system of lectures, training, examination and evaluation, and provide students with 1-8 weeks' internship and practical training every academic year.

3) Optimize resource allocation and meet high-level practical demand

The university will add equipment and instrument and strengthen the construction of professional practice conditions based on the existing experimental center in order to meet the multi-directional and high-level practical demands of university students engaged in "Internet +", robots, drones, integrated circuits, etc., and provide talent reserves for modern industries such as Made in China 2025 Strategy, Industry 4.0.

4) Build learning-oriented organization and promote the train of university students' autonomous learning ability

According to the professional characteristics, it will expand and establish mass organizations closely related to each major, make students experience the "application of their knowledge" in the mass organization practice activities, improve the learning interests, stimulate the innovation ability, and enhance the independent learning ability.
5) Carry out discipline competition and promote practice teaching reform

By participating in various disciplines-related competitions, the reform of the curriculum assessment system will be promoted, and the assessment system of "promoting study with competition and applying competition instead of examination" will be constantly improved. The university will combine the discipline competition with the curriculum assessment, encourage students to participate in the National Undergraduate Electronic Design Contest, the Smart Car Contest, the "Cib-Bot Cup" National IoT Competition, the iCAN IoT Innovation and Entrepreneurship Competition and other professionally-related competitions, take the competition results as a reference to the curriculum assessment and stimulate students' potential and motivation.

\section{IMPLEMENT INNOVATION AND ENTREPRENEURSHIP EDUCATION AND ACHIEVE COLLABORATIVE EDUCATION}

The university will reform the teaching modes and methods combining the characteristics of innovation and strong practicability of electronic information major, and put emphasis on the training of innovative and entrepreneurial applied talents. The students are required to be thoughtful, good at accepting new things, have strong ability to acquire information, dare to develop and innovate in thinking, and focus on training innovative and entrepreneurial applied talents in teaching and practice.

\section{A. Create a strong atmosphere of innovation and entrepreneurship, and stimulate students to form innovation thinking}

Improve the practicality of practice and innovation by working with enterprises; Invite successful alumni in entrepreneurship to share entrepreneurial experience and enhance the initiative of students' innovation; Provide space and platform, gather students with innovative will, carry out thinking collision, and promote the development of innovation and entrepreneurship education.

\section{B. Build an innovation and practice platform to expand students' innovation and entrepreneurship thinking}

Build an innovation and practice platform through the innovation of management mechanism, equipment with professional instructing teachers, provision of good infrastructure and innovation and entrepreneurship environment, and attract students at various majors to participate and incubate the innovation projects; Carry out innovation and entrepreneurship competitions, such as the Internet Technology Innovation Competition, and stimulate students' innovation and entrepreneurship thinking. Construct a crowd innovation community with "Internet + " as a carrier, reflect the characteristics of specialization, integration, marketization and networking, and emphasize the combination of innovation and entrepreneurship, online and offline as well as incubation and investment. 
C. Give full play to the advantages of financial and economic schools and strengthen students' innovation and practice ability

Set up a team of innovation and entrepreneurship instructor team served by "double-teacher type" teachers and external lecturers hired from the enterprises, guide students to butt with professional knowledge, innovation technology and market demand, and inspire students' innovation and entrepreneurship thinking; Give full play to the advantages of the financial and economic schools of the university, and enable the innovation and entrepreneurship team to have a technical, economic and management knowledge reserve through the teaching of professional knowledge such as economics, management and other disciplines by the professional teachers in economics and management, and provide them with the ability to develop the complete innovation and entrepreneurship plan; Invite enterprise instructors to share entrepreneurial experience and cases and enhance students' innovation and entrepreneurship practice ability.

\section{Creat innovation and entrepreneurship education situations in the university}

Our university has signed a strategic cooperation agreement with China Science \& Merchants Capital Management Group and Laishan District Government in respect of the establishment of Academy of Entrepreneurship Zhong Ke which has cooperated with Yantai Dingzhen ECommerce Co., Ltd. and signed an agreement on Yantai Zhongchaung Center Project with Zhifu District People's Government, and the University Student Entrepreneurship Center of Shandong Technology and Business University has been ranked as the provincial-level university student entrepreneurship incubation demonstration base university

\section{CONCLUSION}

The Electronic and Information Engineering Major of Shandong Technology and Business University has constructed a teaching system mainly based on the training of innovation and practice ability, which has effectively improved students' practice ability and innovation ability, and significantly improved the employability, employment quality and employment rate of graduates. With the changes in the demand for electronic information talents in the information society, the practical teaching system should also be continuously improved.

\section{REFERENCES}

[1] Guanglin LI, Hongkui CAO and Weiguo GUAN. Training Mode of Innovative and Applied Talents in Electronic and Information Engineering [J]. Journal of Higher Education, 2018, (1).

[2] Kaixin LI, Shixin LI and Yang CAO. The Reaching Reform on Electronic and Information Engineering and Talent Training Mode [J]. Education and Teaching Forum, 2018, (2).

[3] Yi YIN. Research on Teaching Reform of Electronic and Information Major [J]. Electronic Production, 2016, (12).

[4] Yingwang XIAO. The Construction of Practical Teaching System for Applied Talents in Electronic and Information Engineering [J]. Journal of Changchun University of Science and Technology (Social Science Version ), 2009, 22 (4) 